\title{
Effect of Mediterranean and Occidental Diets, and Red Wine, on Plasma Fatty Acids in Humans. An Intervention Study
}

\author{
INÉS URQUIAGA ${ }^{1}$, VIVIANA GUASCH ${ }^{1}$, GUILLERMO MARSHALL ${ }^{2}$, ALEJANDRA \\ SAN MARTÍN ${ }^{1}$, ÓSCAR CASTILLO ${ }^{3}$, JAIME ROZOWSKI ${ }^{3}$ and FEDERICO LEIGHTON ${ }^{1}$
}

\author{
${ }^{1}$ Molecular Nutrition Laboratory, Faculty of Biological Sciences, Catholic University of Chile, Santiago, Chile \\ 2 Department of Public Health, Faculty of Medicine, Catholic University of Chile, Santiago, Chile \\ ${ }^{3}$ Department of Nutrition, Diabetes and Metabolism, Faculty of Medicine, Catholic University of Chile, \\ Santiago, Chile
}

\begin{abstract}
The type of diet consumed by individuals has been associated with the development of some chronic diseases, including cardiovascular disease (CVD), cancer, diabetes, and others.

Populations that consume diets rich in fruits and vegetables and drink wine in moderation, as the Mediterranean, have a higher life expectancy and less chronic diseases than other occidental populations. We carried out an intervention study in humans to evaluate the effect of a Mediterranean diet (MD), an Occidental diet (OD) and their supplementation with red wine, on biochemical, physiological and clinical parameters related to atherosclerosis and other chronic diseases. For 3 months, two groups of 21 male volunteers each, received either a MD or an OD; during the second month, red wine was added isocalorically, $240 \mathrm{ml} / \mathrm{day}$. At days 0,30, 60 and 90, clinical, physiological and biochemical evaluations were made. In this article we report on the results obtained in plasma fatty acids profile that includes saturated fatty acids (SFA),

monounsaturated fatty acids (MUFA), polyunsaturated fatty acids (PUFA), $\omega-6$ fatty acids, $\omega$ - 3 fatty acids and $\omega-6 / \omega-3$ ratio. Other results have been published previously. Plasma fatty acid percentages in the OD group, compared to the MD group, did not show differences in SFA, but the OD group showed lower levels of MUFA and $\omega-3$ fatty acids, and higher levels of PUFA and $\omega-6$ fatty acids, with a higher $\omega-6 / \omega-3$ ratio than the MD group. Wine supplementation reduced MUFA and increased PUFA in both dietary groups, suggesting that wine could improve a diet with a good $\omega-6 / \omega-3$ ratio. Volunteers on MD showed a better fatty acid profile than those on OD, suggesting a lower cardiovascular risk. Moderate consumption of wine improves this profile in the MD group.
\end{abstract}

Key words: Cardiovascular disease, chronic diseases, fatty acids, Mediterranean diet, monounsaturated fatty acids (MUFA), Occidental diet, $\omega-6$ fatty acids, $\omega-3$ fatty acids, plasma fatty acids, polyunsaturated fatty acids (PUFA), saturated fatty acids (SFA), wine.

Abbreviations: CVD: cardiovascular disease; MD: Mediterranean diet; MUFA: monounsaturated fatty acids; OD: Occidental diet; PUFA: polyunsaturated fatty acids; ROS: reactive oxygen species; SFA: saturated fatty acids.

\section{INTRODUCTION}

Diet is a key factor in the control and development of chronic diseases, including cardiovascular disease (CVD), cancer, diabetes and others (Buzina R et al., 1991; Halliwell B, 1997; Satia-Abouta et al., 2002). Atherosclerosis and cancer are the main causes of death in industrialized countries (WHO).

Since Mediterranean basin populations show a lower mortality rate from all causes, as well as a low specific mortality from CVD, phenomena which could partially be explained by their dietary habits, the Mediterranean diet has often been proposed

Corresponding Author: Inés Urquiaga. Laboratorio de Nutrición Molecular, Departamento de Biología Celular y Molecular, Facultad de Ciencias Biológicas, Pontificia Universidad Católica de Chile. Alameda 340, Santiago, Chile. Phone/Fax: (56-2) 222 2577. E-mail: <iurquiag@ bio.puc.cl> 
as a prototype or dietary paradigm on which dietary recommendations for the prevention of CVD may be based (Ferro-Luzzi A and Brabca F, 1995; Trichopoulou A, 2003). In contrast, most other Occidental developed countries show a high risk of chronic diseases, so their diet has been catalogued as inconvenient and as a risk factor for chronic diseases (Berrino F, 2002; Linseisen J, 2002; Simopoulos AP, 2002).

The diet of the people from the Mediterranean countries of Southern Europe is characterized by a relatively high consumption of fish, white meat, olive oil, legumes, vegetables and fruits, by a lower consumption of red meat and animal fat and by a moderate consumption of red wine with meals. Conversely, the Occidental diet, characteristic of the USA and some other continental and Northern European populations, is defined by a high dietary intake of red meat, animal fat, dairy products and sugar, and by decreased consumption of legumes, vegetables and fruits and, in several populations, of sea food. In terms of nutrients the Mediterranean diet is rich in monounsaturated fatty acids (MUFA), fiber and antioxidants; it is balanced in $\omega-6 / \omega-3$ polyunsaturated fatty acids (PUFA) and low in saturated fat (SFA). The Occidental diet is high in SFA and $\omega-6$ fatty acids, high in refined or simple carbohydrates and poor in antioxidants and fiber.

Oxidative stress, the consequence of a prooxidant imbalance between prooxidants and antioxidants in the human body, has been implicated during the last decade in the pathogenesis of chronic diseases and aging (Urquiaga I and Leighton F, 2000; Alvarado C et al., 2003). Since antioxidants reduce or suppress oxidative stress, they could prevent the damage caused by reactive oxygen species (ROS) and decrease the risk of chronic diseases (Ames BN, 1993). Also, there is abundant evidence from experimental, clinical and epidemiological observations that $\omega-3$ fatty acids protect against atherosclerosis and sudden coronary death (Mori TA and Beilin LJ, 2001).

In this context, the benefits of Mediterranean diets have been attributed to a large consumption of antioxidants provided by fruits, vegetables and wine and to the type of fat, especially MUFA and $\omega-3$ fatty acids from vegetables and fish (Trichopoulous A et al., 1999; Simopoulos AP, 2001; Simopoulos AP, 2004). The damage potential of Occidental diets has been associated to a high intake of SFA and $\omega-6$ fatty acids from red meat, dairy products and some vegetable oils (Mata $\mathrm{P}$ et al., 1996; Lahoz C et al., 1997; Willet WC, 1997; de Wilde et al., 2002; Simopoulos AP, 2002; Valenzuela A et al., 2003). PUFA are susceptible to ROS and are oxidized to lipid peroxides, generating chain reactions that cause extensive damage to DNA, protein, carbohydrates and lipids.

Plasma fatty acids are markers for dietary fat composition. It has been shown that the pattern of fatty acids in plasma lipid reflects the dietary fat composition, especially PUFA and SFA during the previous week (Ma J et al., 1995; Nikkari T et al., 1995; Katan MB et al., 1997). The content of fatty acids in human tissues is dependent not only on dietary intake, but also on the endogenous synthesis and metabolism of fatty acids, and on genetic disposition (Vessby B, 2003). Kinetics of incorporation and elimination of several fatty acids are different and also depend on the type of tissue (Katan MB et al., 1997).

In order to compare the effect of MD and OD, plus their supplementation with red wine, on biochemical, physiological, and clinical parameters related to atherosclerosis and other chronic diseases, we carried out an intervention study in humans. In this paper, we analyze the results obtained in plasma fatty acids. Other evaluations as plasma antioxidants, plasma antioxidant capacity and oxidative damage markers will be matter of another publication. Results on hemostatic factors have been published previously (Mezzano et al., 2001; Mezzano et al., 2003; Mezzano et al., 2004).

\section{METHODS}

\section{Study design}

The subjects of this intervention study were 42 healthy young males aged $22 \pm 3.4$ 
years, who previously consumed an omnivorous diet. All volunteers were in good health as determined by a medical history questionnaire, a physical examination, and the results of clinical laboratory tests.

For 3 months, 2 groups of 21 male volunteers each received either MD or OD; during the second month of diet, red wine was added isocalorically, $240 \mathrm{ml} /$ day. At days $0,30,60$ and 90, clinical, physiological and biochemical parameters were evaluated. The experimental protocol was approved by the Ethics Committee of the Faculty of Medicine.

The subjects and the design of this intervention study have been previously described in greater detail (Mezzano et al., 2001). A diagram with the design of the intervention study is shown in Figure 1.

DIETS

The MD was designed according to reported feeding patterns from Mediterranean countries (Ferro-Luzzi A and Branca F, 1995; Helsing E, 1995). The OD was modeled after the average US diet of the late 1970's (Browner WS et al., 1991). The composition of these diets is shown in Tables I and II. The diets were prepared by a private caterer under the daily supervision of the team nutritionist and a bacteriologist. Diet composition was calculated employing Food Processor II computer program (ESHA Research, Salem, OR).

The wine utilized in the study was a Chilean Cabernet Sauvignon, 1997, from a Maipo Valley vineyard. It contained $12 \%$ (by volume) of alcohol. The total polyphenol

\section{STUDY DESIGN}
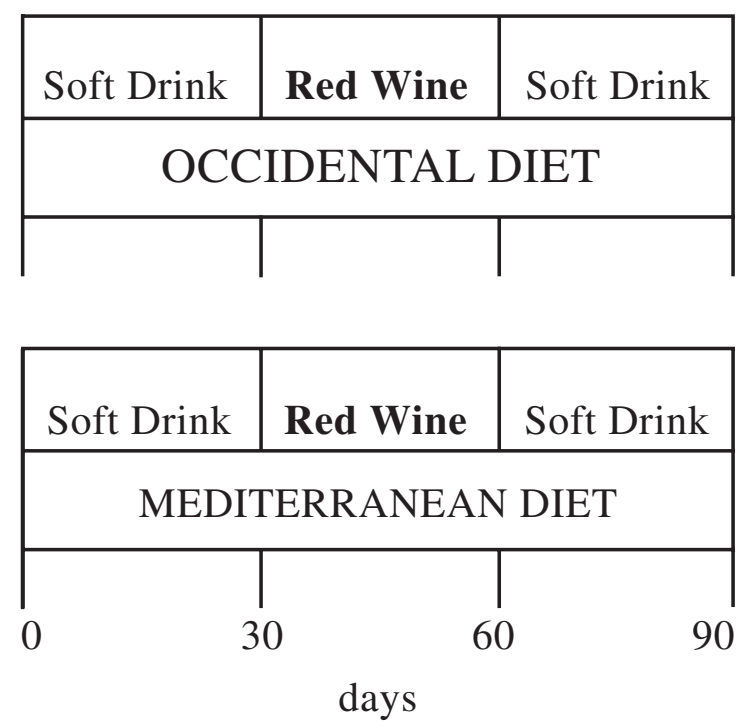

Figure 1. Experimental design of the study.

TABLE I

Average daily intake of food and energy supply in the Occidental and Mediterranean diet groups.

\begin{tabular}{lrc}
\hline & Occidental & Mediterranean \\
\hline Energy intake (kcal) & 2600 & 2565 \\
\% Energy as fat & 39.9 & 27.3 \\
\% Energy as carbohydrate & 42.8 & 55.1 \\
\% Energy as protein & 17.5 & 17.6 \\
Fruits and vegetables $(\mathrm{g} / \mathrm{d})$ & 246 & 675 \\
Fish and chicken $(\mathrm{g} / \mathrm{d})$ & 74 & 157 \\
Beef and pork (g/d) & 209 & 59.3 \\
Fiber (g/d) & 12 & 44 \\
Bread, cereals, legumes $(\mathrm{g} / \mathrm{d})$ & 261 & 311 \\
Oil (ml) & 32 (sunflower) & 32 (olive) \\
\hline
\end{tabular}


TABLE II

Average daily intake of fatty acids in the Occidental and Mediterranean diet groups.

\begin{tabular}{lcccc}
\hline & \multicolumn{2}{c}{ Occidental } & \multicolumn{2}{c}{ Mediterranean } \\
\cline { 2 - 5 } & $\mathrm{g} / \mathrm{d}$ & $\%$ & $\mathrm{~g} / \mathrm{d}$ & $\%$ \\
\hline Total fat & 112.7 & 100 & 77.0 & 100 \\
SFA * & 35.8 & 31.8 & 22.7 & 29.5 \\
MUFA & 35.5 & 31.5 & 37.9 & 49.2 \\
PUFA & 32.0 & 28.4 & 9.6 & 12.5 \\
$\omega$-3 fatty acids & 0.96 & 0.85 & 1.64 & 2.13 \\
\hline
\end{tabular}

*SFA: Saturated fatty acids; MUFA: Monounsaturated fatty acids;

PUFA: Polyunsaturated fatty acids; $\omega$-3 fatty acids $=\alpha$-linolenic acid + eicosapentaenoic acid + docosapentaenoic acid + docosahexaenoic acid. g/d: daily intake in grams.

content of this wine (expressed as gallic acid equivalents) was $1,850 \mathrm{mg} / \mathrm{L}$. During the wine period, each volunteer was asked to drink the wine, $240 \mathrm{ml} /$ day (equivalent to $23.2 \mathrm{~g}$ of alcohol), with meals.

\section{Analytical Procedures}

Venous blood samples were collected at 0 , 30, 60 and 90 days after a 12-hour fasting period into heparin, citrate, or anticoagulant-free tubes. Plasma, serum, erythrocyte and leukocyte samples were stored following common laboratory procedures until they were analyzed. Plasma was obtained from freshly drawn blood by centrifugation at $1000 \mathrm{x} \mathrm{g}$ for 5 min. Aliquots of plasma were stored at $70^{\circ} \mathrm{C}$ before analysis.

\section{Fatty acid analysis}

Lipids were extracted from $200 \mu \mathrm{L}$ plasma by the method of Bligh and Dyer (Bligh EG and Dyer WJ, 1959) using $5 \mathrm{ml}$ of chloroform/methanol (2: 1, v: v) containing $0.01 \%$ butylated hydroxytoluene. A known amount of pentadecaenoic acid (15: 0) was added as an internal standard. Total fatty acids were trans-esterified overnight at room temperature with $1 \mathrm{mmol} / \mathrm{L}$ methanolic- $\mathrm{HCl}$. After extraction with nhexane the methyl esters were separated and quantified by a GC-6000 Megaseries gas-liquid chromatograph (Carlo Erba, Italy) equipped with a $50 \mathrm{~m} \mathrm{x} 0.25 \mathrm{~mm}$ capillary column (SGE BPX-70) using hydrogen as carrier gas. The oven temperature was programmed to increase $5^{\circ} \mathrm{C} / \mathrm{min}$ from 110 to $230^{\circ} \mathrm{C}$. The resultant peaks were identified by comparing the retention times with those of known fatty acid methyl ester standards. Peak areas were determined by automatic integration (Spectra Physics, San José, California, USA).

\section{Statistical analysis}

Two-tailed unpaired Student's $t$-test or Mann-Whitney test were used to compare the means of different variables between MD and OD groups at baseline. Proportions were compared by two-tailed, Fisher's exact test. A linear mixed effects model (repeated measure ANOVA) (Verdeke G and Molenberghs G, 1997) was used to compare both diets and the effect of wine on the different variables during the study period at 30, 60 and 90 days. To correct for small group differences explained by between-subject variability and to adjust for lack of absolute randomization, the values at 30 , 60 and 90 days were controlled by the baseline measurement, which was used in the model as a covariate. An ANOVA-type $F$-statistic was calculated to test the effect of diet (MD vs OD) across the study time (30, 60 and 90 days), controlling by the initial values. The effect of wine, combining the two dietary groups, was 
evaluated comparing response of all subjects at T60 vs the average values at T30 and T90 using an $F$-statistic based on within-subject source of variability. Also, to control for a longer than expected wine effect, the response at T60 vs values at T30 were compared. Finally, the wine effect was also tested for each dietary group independently, despite loss of statistical power. Normal distribution was checked on the residual of all variables considered in this work. In those cases in which a departure from the normality assumption was detected, a similar analysis was performed using the rank statistics instead of the raw data, as a nonparametric alternative of the same analysis. The proc MIXED of the SAS statistical program was used for these purposes.

\section{RESULTS}

Table I shows the average daily intake of food and energy supply in the OD and MD groups. Energy intake in both groups was the same. The MD was characterized by a relatively high intake of fruits and vegetables, low quantities of red meats, and the use of olive oil. By contrast, the OD provided a low amount of fruits and vegetables, mainly red meat, low fiber, and sunflower oil, mayonnaise, and dairy cream. In terms of macronutrients, the MD contained less energy as fat and more as carbohydrates than the OD, while protein content was the same for both diets. The difference in fat was principally due to more SFA and PUFA in OD than in MD (Table II). But the composition in PUFA was also different; MD contained more $\omega$-3 fatty acids than OD, so $\omega-6 / \omega-3$ balance was approximately 32 and 5 in $\mathrm{OD}$ and $\mathrm{MD}$, respectively.

Despite lack of absolute randomization, no significant differences were observed at baseline (T0) for most of the parameters studied (Mezzano et al., 2001) included plasma percentage of MUFA, PUFA, $\omega-6$ fatty acids and $\omega-6 / \omega-3$ ratio between the OD group and the MD group. However, significant differences were observed in plasma percentage of SFA and $\omega-3$ fatty acids. For that reason, differences at T0 were corrected in our statistical analyses as explained in Methods.

Results are depicted in Table III. The effect of diet (MD vs OD) throughout the study time (T30, T60, T90) showed no significant differences between dietary groups in average plasma percentage of SFA $\left(P_{d}=0.092\right)$. OD group had lower levels of MUFA $\left(\mathrm{P}_{\mathrm{d}}=0.001\right)$ and $\omega-3$ fatty acids $\left(\mathrm{P}_{\mathrm{d}}<0.001\right)$, and higher levels of PUFA $\left(\mathrm{P}_{\mathrm{d}}=0.001\right)$ and $\omega-6$ fatty acids $\left(\mathrm{P}_{\mathrm{d}}<0.001\right)$ than the MD group. Also, the $\omega$ $6 / \omega-3$ ratio $\left(\mathrm{P}_{\mathrm{d}}<0.001\right)$ was higher in OD group than in the MD group.

The effect of wine was evaluated combining the results of both dietary groups $(\mathrm{N}=42)$ and comparing the response of all subjects at T60 vs T30 and T60 vs (T30 + T90)/2. Red wine consumption was associated with a reduction in MUFA $\left(\mathrm{P}_{\mathrm{w} 60}<0.001\right.$ and $\mathrm{P}_{\mathrm{w} 60 / 2}<0.001$, respectively) and an increase in PUFA $\left(\mathrm{P}_{\mathrm{w} 60}<0.001\right.$ and $\mathrm{P}_{\mathrm{w} 60 / 2}<0.001$, respectively) and in $\omega-6$ fatty acids $\quad\left(\mathrm{P}_{\mathrm{w} 60}<0.001\right.$ and $\mathrm{P}_{\mathrm{w} 60 / 2}=0.010$, respectively). Wine withdrawal showed a possible residual effect of wine (T30 vs T90) on these variables $\left(\mathrm{P}_{30-90}<0.001, \mathrm{P}_{30-90}=0.016\right.$, and $\mathrm{P}_{30-90}<0.001$, respectively), because T90 percentages did not reach $\mathrm{T} 30$ percentages.

The effect of wine on the percentage of SFA combining the results of both dietary groups showed a statistically significant decrease when comparing 60 vs $(30+$ $90) / 2\left(\mathrm{P}_{\mathrm{w} 60 / 2}<0.048\right)$, but not 60 vs 30 $\left(\mathrm{P}_{\mathrm{w} 60}=0.472\right)$. Wine withdrawal showed a possible residual effect of wine (T30 vs T90) on this variable $\left(\mathrm{P}_{30-90}=0.045\right)$. Similarly, the percentage of plasma $\omega-3$ fatty acids showed a statistically significant increase when comparing 60 vs $(30+90) / 2\left(\mathrm{P}_{\mathrm{w} 60 / 2}<0.001\right)$, but not 60 vs $30 \quad\left(P_{w 60}=0.233\right)$. Also, wine withdrawal showed a possible residual effect of wine (T30 vs T90) on this variable $\left(\mathrm{P}_{30-90}<0.001\right)$.

When the dietary groups were analyzed independently, wine consumption decreased significantly the SFA plasma percentage only in the MD group for the comparison $\mathrm{T} 60$ vs $\mathrm{T} 30+\mathrm{T} 90 / 2\left(\mathrm{P}_{\mathrm{w} 60 / 2}=0.043\right)$ but 
TABLE III

Effects of Occidental and Mediterranean type diets, with (T60) and without (T30 and T90) red wine, on fatty acids in young healthy volunteers. Basal values at T0.

\begin{tabular}{|c|c|c|c|c|c|c|c|}
\hline Variable/Time (d) & & 0 & 30 & 60 & 90 & $\mathrm{P}_{\text {diet }}$ & $\mathrm{P}_{\text {wine }}$ \\
\hline \multirow[t]{2}{*}{ SFA $(\%)^{\mathbf{a}}$} & OD & $28.34 \pm 2.28$ & $28.92 \pm 2.73$ & $29.04 \pm 1.69$ & $29.82 \pm 2.34$ & \multirow[t]{2}{*}{0.092} & \multirow[t]{2}{*}{$0.472^{b}$} \\
\hline & MD & $26.65 \pm 2.34$ & $30.11 \pm 2.49$ & $29.14 \pm 2.78^{c}$ & $31.57 \pm 4.10$ & & \\
\hline \multirow{2}{*}{ MUFA (\%) } & OD & $18.41 \pm 2.15$ & $21.00 \pm 2.78$ & $18.39 \pm 2.52$ & $18.60 \pm 2.71$ & \multirow[t]{2}{*}{0.01} & \multirow[t]{2}{*}{$<0.001$} \\
\hline & MD & $18.81 \pm 3.50$ & $23.35 \pm 2.14$ & $21.05 \pm 3.10$ & $20.87 \pm 1.87$ & & \\
\hline \multirow[t]{2}{*}{ PUFA (\%) } & OD & $47.55 \pm 3.77$ & $45.85 \pm 4.55$ & $49.32 \pm 3.36$ & $48.15 \pm 4.30$ & \multirow[t]{2}{*}{0.01} & \multirow[t]{2}{*}{$<0.001$} \\
\hline & MD & $45.09 \pm 9.24$ & $42.49 \pm 3.76$ & $45.43 \pm 4.06$ & $43.72 \pm 5.56$ & & \\
\hline \multirow[t]{2}{*}{$\omega-3(\%)^{\mathbf{a}}$} & OD & $4.74 \pm 1.22$ & $4.96 \pm 1.02$ & $4.84 \pm 1.05$ & $4.18 \pm 0.75$ & \multirow[t]{2}{*}{$<0.001$} & \multirow[t]{2}{*}{$0.233^{\mathbf{b}}$} \\
\hline & MD & $6.10 \pm 1.58$ & $6.45 \pm 1.81$ & $7.27 \pm 2.45^{\mathrm{c}}$ & $4.92 \pm 1.20$ & & \\
\hline \multirow[t]{2}{*}{$\omega-6(\%)$} & OD & $42.81 \pm 3.69$ & $41.13 \pm 4.14$ & $44.78 \pm 3.22$ & $43.99 \pm 4.17$ & \multirow[t]{2}{*}{$<0.001$} & \multirow[t]{2}{*}{0.010} \\
\hline & MD & $41.07 \pm 4.28$ & $36.04 \pm 3.84$ & $38.16 \pm 4.55$ & $38.81 \pm 5.30$ & & \\
\hline \multirow[t]{2}{*}{$\omega-6 / w-3(\%)$} & OD & $9.64 \pm 2.68$ & $8.57 \pm 1.73$ & $9.56 \pm 1.63$ & $10.84 \pm 2.25$ & \multirow[t]{2}{*}{$<0.001$} & \multirow[t]{2}{*}{$0.163^{b}$} \\
\hline & MD & $7.15 \pm 1.93$ & $6.05 \pm 1.92$ & $6.10 \pm 3.10$ & $8.29 \pm 2.12$ & & \\
\hline
\end{tabular}

Abbreviations: SFA, saturated fatty acids; MUFA, monounsaturated fatty acids; PUFA, polyunsaturated fatty acids; $\omega-3=18: 3 n 3+20: 5 n 3+22: 5 n 3+22: 6 n 3 ; \omega-6=18: 2 n 6+18: 3 n 6+20: 2 n 6+20: 3 n 6+20: 4 n 6+$ 22:4n6.

Data represent mean \pm s.d. of observed values.

$\mathrm{P}_{\text {diet }}$ : Effect of diet was evaluated by repeated measure ANOVA, controlling by the initial values and comparing both dietary groups at 30,60 and 90 days.

$\mathrm{P}_{\text {wine }}$ : Effect of wine was evaluated combining groups (OD and MD) and comparing their response at 60 vs 30 as well as $60 v s(30+90) / 2$. The P-value shown is the less significant of both calculations.

a Comparison of values at 0 between OD and MD for SFA and $\omega-3$ was statistically significant, for the other variables comparison was not statistically significant (two-tailed, unpaired Student's $t$-test or Mann-Whitney test).

b Denotes statistically significant effect of wine for a specific type of comparing, 60 vs 30 or 60 vs $(30+90) / 2$.

Both groups for $60 \mathrm{vs}(30+90) / 2$ on SFA\% $\mathrm{P}_{\mathrm{w} 60 / 2}<0.048$. Both groups for $60 \mathrm{vs}(30+90) / 2$ on $\omega-3 \%$

$\mathrm{P}_{\mathrm{w} 60 / 2}<0.001$. Both groups for $60 \mathrm{vs}(30+90) / 2$ on $\omega-6 / \omega-3 \% \mathrm{P}_{\mathrm{w} 60 / 2}=0.063$.

c Denotes statistically significant effect of wine in an individual dietary group. Effect of MD-wine on SFA \% $\left(\mathrm{P}_{\mathrm{w} 60 / 2}=0.043\right)$; OD-wine on SFA \% $\left(\mathrm{P}_{\mathrm{w} 60 / 2}=0.390\right)$; of MD-wine on $\omega-3 \%(\mathrm{P}=0.002)$; of OD-wine on $\omega-3 \%$ $\left(\mathrm{P}_{\mathrm{w} 60 / 2}=0.183\right)$.

not T60 vs T30 ( $\left.\mathrm{P}_{\mathrm{w} 60}=0.308\right)$. Also, percentage of plasma $\omega-3$ fatty acids increased significantly after wine consumption in the MD group for the comparison $\mathrm{T} 60$ vs $\mathrm{T} 30+\mathrm{T} 90 / 2\left(\mathrm{P}_{\mathrm{w} 60 / 2}=\right.$ $0.002)$ but not $\mathrm{T} 60$ vs T30 $\left(\mathrm{P}_{\mathrm{w} 60}=0.134\right)$. Wine withdrawal decreased $\omega-3$ fatty acids percentage below diet alone (T30) in both experimental groups $\left(\mathrm{P}_{30-90}=0.002\right.$ and $\mathrm{P}_{30-90}=0.007$, T30 vs T90 for OD and MD respectively).

The $\omega-6 / \omega-3$ ratio showed an increase along the study period $\left(\mathrm{P}_{t}<0.001\right)$ for both diets. Diet strongly influences the ratio, yet it is quite clear that the MD group had an initial lower ratio.

\section{DISCUSSION}

The results showed that plasma levels of fatty acids in volunteers depend on the type of fat ingested. MD contained proportionally more MUFA and less PUFA than OD, and this was reflected in plasma proportion of these fatty acids in volunteers. The composition in PUFA was different in both diets; MD contained more $\omega-3$ fatty acids and less $\omega-6$ fatty acids than OD. Accordingly, the plasma percentage of $\omega-3$ fatty acids was higher and $\omega-6$ fatty acids lower in the MD group than in the OD group. The proportion of SFA was almost equal in both diets. 
Red wine consumption produced changes in the proportion of plasma fatty acids, raising PUFA and lowering MUFA in both dietary groups, and lowering SFA in the MD group. Specifically, red wine increased plasma levels of $\omega-6$ fatty acids in both diets and $\omega-3$ fatty acids only in the MD group. Therefore on MD, red wine produced two healthy effects, diminishing the proportion of SFA and increasing the proportion of $\omega-3$ fatty acids. The increase in PUFA in both diet groups could be explained by the antioxidant effect of wine polyphenols in the intestine, protecting the fatty acids from oxidation (Natalla $F$ et al., 2001). An increase of platelet PUFA in humans induced by the non-alcoholic components of red wine has been reported, suggesting an antioxidant effect in this fraction (Pellegrini N et al., 1996).

No effect of wine on SFA or $\omega$-3 fatty acids was observed in the OD group, but a residual effect was noticed in both groups when wine was withdrawn. The lack of effect of wine on the OD may be due to the high proportion of SFA in relation to $\omega-3$ fatty acids present in this diet. OD contained $58 \%$ more SFA, 3.9 times more $\omega$ 6 fatty acids and $42 \%$ less $\omega$-3 fatty acids than MD. To assess if wine produces a specific effect in $\omega-3$ fatty acids needs more investigation, but the fact that during the wine withdrawal period $\omega-3$ fatty acids decreased and the $\omega-6 / \omega-3$ ratio increased, supports this idea. There are some additional evidences: subjects drinking red wine showed a high level of $\omega-6$ fatty acids (arachidonic acid 13 $\%$ ) and $\omega-3$ fatty acids (docosahexaenoic acid $22 \%$ ) in phosphatidylethanolamine from erythrocytes (Simonetti P et al., 1995); subjects drinking red wine or ingesting nonalcoholic components present in red wine, showed a general increase in PUFA and a general decrease in $\omega-6 / \omega-3$ ratio in all platelet phospholipids, with the exception of sphingomyelin; more precisely, the increase in the proportion of $\omega-6$ fatty acids and of $\omega-3$ fatty acids was $10.2 \%$ and $37.5 \%$ in phosphatidylethanolamine, respectively, reflecting a reduction in the $\omega-6 / \omega-3$ ratio, from 8.08 to 6.47 (Pellegrini $\mathrm{N}$ et al., 1996). Also, patients drinking wine showed a high level of $\omega-3$ fatty acids in granulocyte membranes and adipose tissue, and this is related to the diet (Christensen $\mathrm{JH}$ et al., 2001). The finding that wine increases $\omega-3$ fatty acids in plasma is relevant because of the numerous publications that have reported biochemical and physiological effects of $\omega-3$ fatty acids in humans and animals that are expected to prevent or ameliorate CHD (de Lorgeril M et al., 1994; Simopoulos AP, 1997; Mori TA et al., 2001). Studies have also shown potent antiarrhythmic effects of $\omega$-3 fatty acids in animal and in vitro studies (Leaf A et al., 1999), which tend to explain the reduced incidence of sudden cardiac death in humans given $\omega-3$ fatty acids (Christensen $\mathrm{JH}$ and Schmidt EB, 2001).

Plasma fatty acids profile and $\omega-6 / \omega-3$ ratio showed better values in the MD group than in the OD group, a positive result for the prevention of chronic diseases. Wine consumption increases PUFA in both dietary groups; this effect could possibly be better when the $\omega-6 / \omega-3$ ratio in the diet is near 4 , as in MD (Simopoulos AP, 2001), favoring the beneficial effects of $\omega-3$ on cardiovascular disease. In the MD group, wine supplementation decreased the levels of SFA and increased $\omega-3$ fatty acids, changes leading to a lower cardiovascular risk

\section{SUPPORTED BY}

PUC-PBMEC98 (Molecular Basis of Chronic Diseases Program), Catholic University of Chile.

\section{REFERENCES}

ALVARADO C, VÁSQUEZ L, LEIGHTON F. (2003) methionine sulfoxide oxidative stress marker for plasma proteins. XLVI Reunión Anual de la Sociedad de Biología de Chile. Biol Res 36: R-93

AMES BN, SHIGENAGA MK, HAGEN TM (1993) Oxidants, antioxidants, and the degenerative diseases of aging. Proc Natl Acad Sci USA 90: 7915-7922

BLIGH EG, DYER WJ (1959) A rapid method of total lipid extraction and purification. Can J Biochem Physiol 37: 911-917

BROWNER WS, WESTENHOUSE J, TICE JA (1991) What if Americans ate less fat? A quantitative estimate of the effect on mortality. J Am Med Assoc 265: 32853291 
BUZINA R, SUBOTICANEC K, SARIC M (1991) Diet patterns and health problems: diet in southern Europe. Ann Nutr Metab 35 Suppl 1: 32-40

CHRISTENSEN JH, SCHMIDT EB (2001) n-3 fatty acids and the risk of sudden cardiac death. Lipids 36 Suppl: S115-S118. Review

CHRISTENSEN JH, SKOU HA, FOG L, HANSEN VE, VESTERLUND $T$, DYERBERG J, TOFT E, SCHMIDT EB (2001) Marine n-3 fatty acids, wine intake and heart rate variability in patients referred for coronary angiography. Circulation 103: 651-657

DE LORGERIL M, RENAUD S, MAMELLE N, SALEN P, MARTIN JL, MONJAUD I, GUIDOLLET J, TOUBOUL P, DELAYE J (1994) Mediterranean alphalinolenic acid-rich diet in secondary prevention of coronary heart disease. Lancet 343(8911): 1454-1459. Erratum in: Lancet 1995 Mar 18; 345(8951): 738

DE WILDE MC, FARKAS E, GERRITS M, KILIAAN AJ, LUITEN PG. (2002) The effect of n-3 polyunsaturated fatty acid-rich diets on cognitive and cerebrovascular parameters in chronic cerebral hypoperfusion. Brain Res 947(2): 166-173

FERRO-LUZZI A, BRANCA F (1995) Mediterranean diet, Italian-Style: Prototype of a Healthy Diet Am J Clin Nutr 61: 1338S-1345S

HALLIWELL B (1997) Antioxidants and human disease: a general introduction. Nutr Rev. 55(1 Pt 2): S44-9; discussion S49-52

HELSING E (1995) Traditional diets and disease patterns of the Mediterranean. Circa 1960 Am J Clin Nutr 61: 1329S-1337S

KATAN MB, DESLYPERE JP, VAN BIRGELEN AP, PENDERS M, ZEGWAARD M (1997) Kinetics of the incorporation of dietary fatty acids into serum cholesteryl esters, erythrocyte membranes, and adipose tissue: an 18-month controlled study. J Lipid Res 38(10): 2012-2022

KEYS A, MENOTTI A, KARVONEN MJ, ARAVANIS C, BLACKBURN H, BUZINA R, DJORDJEVIC BS, DONTAS AS, FIDANZA F, KEYS MH, et al. (1986) The diet and 15-year death rate in the seven countries study Am J Epidemiol 24(6): 903-915

LAHOZ C, ALONSO R, ORDOVAS JM, LÓPEZ-FARRE A, DE OYA M, MATA P (1997) Effects of dietary fat saturation on eicosanoid production, platelet aggregation and blood pressure. Eur J Clin Invest 27(9): 780-787

LEAF A, KANG JX, XIAO YF, BILLMAN GE (1999) n-3 fatty acids in the prevention of cardiac arrhythmias. Lipids 34 Suppl: S187-S189. Review

LINSEISEN J, BERGSTROM E, GAFA L, GONZÁLEZ CA, THIEBAUT A, TRICHOPOULOU A, TUMINO R, NAVARRO SÁNCHEZ C, MARTÍNEZ GARCÍA C, MATTISSON I, NILSSON S, WELCH A, SPENCER EA, OVERVAD K, TJONNELAND A, CLAVELCHAPELON F, KESSE E, MILLER AB, SCHULZ M, BOTSI K, NASKA A, SIERI S, SACERDOTE C, OCKE MC, PEETERS PH, SKEIE G, ENGESET D, CHARRONDIERE UR, SLIMANI N (2002) Consumption of added fats and oils in the European Prospective Investigation into Cancer and Nutrition (EPIC) centres across 10 European countries as assessed by 24-hour dietary recalls. Public Health Nutr 5(6B): 1227-1242

MA J, FOLSOM AR, SHAHAR E, ECKFELDT JH (1995) Plasma fatty acid composition as an indicator of habitual dietary fat intake in middle-aged adults. The Atherosclerosis Risk in Communities (ARIC) Study Investigators.Am J Clin Nutr 62(3): 564-571
MATA P, ALONSO R, LÓPEZ-FARRE A, ORDOVAS JM, LAHOZ C, GARCÉS C, CARAMELO C, CODOCEO R, BLÁZQUEZ E, DE OYA M (1996) Effect of dietary fat saturation on LDL oxidation and monocyte adhesion to human endothelial cells in vitro. Arterioscler Thromb Vasc Biol 16(11): 1347-1355

MEZZANO D, LEIGHTON F, MARTÍNEZ C, MARSHALL G, CUEVAS A, CASTILLO O, PANES O, MUÑOZ B, PÉREZ DD, MIZON C, ROZOWSKI J, SAN MARTÍN A, PEREIRA J (2001) Complementary effects of Mediterranean diet and moderate red wine intake on haemostatic cardiovascular risk factors. Eur J Clin Nutr 55(6): 444-451

MEZZANO D, LEIGHTON F, STROBEL P, MARTÍNEZ C, MARSHALL G, CUEVAS A, CASTILlO O, PANES O, MUÑOZ B, ROZOWSKI J, PEREIRA J (2003) Mediterranean diet, but not red wine, is associated with beneficial changes in primary haemostasis. Eur J Clin Nutr 57(3): 439-446

MEZZANO D (2004) Distinctive Effects of Red Wine and Diet on Haemostatic Cardiovascular Risk Factors. Biol Res 37: 217-224

MORI TA, BEILIN LJ (2001) Long-chain omega 3 fatty acids, blood lipids and cardiovascular risk reduction. Curr Opin Lipidol 12(1): 11-17. Review

NATALLA F, GHISELLI A, URSINI F, SCACCINI C (2001) Red wine mitigates the postprandial increase of LDL susceptibility to oxidation. Free Radic Biol Med 30: $1036-1044$

NIKKARI T, LUUKKAINEN P, PIETINEN P, PUSKA P (1995) Fatty acid composition of serum lipid fractions in relation to gender and quality of dietary fat. Ann Med. 27(4): 491-498

PELLEGRINI N, SIMONETTI P, BRUSAMOLINO A, BOTTASSO B, PARETI FI (1996) Composition of platelet phospholipids after moderate consumption of red wine in healthy volunteers. Eur J Clin Nutr 50(8): $535-544$

SATIA-ABOUTA J, PATTERSON RE, NEUHOUSER ML, ELDER J (2002) Dietary acculturation: applications to nutrition research and dietetics. J Am Diet Assoc. 102(8): 1105-1118

SIMONETTI P, BRUSAMOLINO A, PELLEGRINI N, VIANI P, CLEMENTE G, ROGGI C, CESTARO B (1995) Evaluation of the effect of alcohol consumption on erythrocyte lipids and vitamins in a healthy population. Alcohol Clin Exp Res 19(2): 517-522

SIMOPUOLOS AP (1997) Omega-3 fatty acids in the prevention-management of cardiovascular disease. Can J Physiol Pharmacol 75(3): 234-239. Review

SIMOPOULOS AP (2001) The Mediterranean diets: What is so special about the diet of Greece? The scientific evidence. J Nutr 131 (11 Suppl): 3065S3073S. Review

SIMOPOULOS AP (2002) Omega-3 fatty acids in inflammation and autoimmune diseases. J Am Coll Nutr 21(6): 495-505. Review

SIMOPOULOS AP (2004) Omega-3 Fatty Acids and Antioxidants in Edible Wild Plants. Biol Res 37: 263-277

TRICHOPOULOU A, COSTACOU T, BAMIA C, TRICHOPOULOS D (2003) Adherence to a Mediterranean diet and survival in a Greek population. N Engl J Med 26; 348(26): 2599-2608

URQUIAGA I, LEIGHTON F. (2000) Plant polyphenol antioxidants and oxidative stress. Biol Res 33: 55-64

VALENZUELA A, SANHUEZA J, NIETO S. (2003) Cholesterol oxidation: health hazard and the role of antioxidants in prevention. Biol Res 36: 291-302 
VERDEKE G, MOLENBERGHS G (1997) Linear Mixed Models in Practice: a SAS-oriented Approach. New York: Springer

VESSBY B (2003) Dietary fat, fatty acid composition in plasma and the metabolic syndrome. Curr Opin Lipidol 14(1): $15-19$
WILLET WC (1997) Specific fatty acids and risks of breast and prostate cancer: dietary intake. Am J Clin Nutr 66(6 Suppl): 1557S-1563S 